\section{Commentary: Coronary artery bypass surgery and percutaneous coronary intervention: Optimal revascularization for the younger patient}

\author{
Rodolfo V. Rocha, MD, ${ }^{\text {a }}$ Malak Elbatarny, MD, ${ }^{\text {a }}$ \\ Derrick Y. Tam, MD, ${ }^{\mathrm{a}, \mathrm{b}}$ and \\ Stephen E. Fremes, MD, MSc ${ }^{a, b}$
}

Coronary artery bypass surgery $(\mathrm{CABG})$ was the first reliable intervention to treat coronary artery disease until percutaneous coronary intervention (PCI) emerged. ${ }^{1,2}$ There has been more 30 years of debate over which coronary revascularization strategy yield better results. ${ }^{3,4}$ Several randomized controlled trials (RCTs) have compared these techniques, with CABG typically having greater early risk but providing more complete revascularization, and hence, better long-term outcomes compared with PCI, especially for patients diabetes or with complex coronary anatomy. ${ }^{5,6}$ However, RCTs have certain disadvantages, despite being considered the holy grail of medical science. First, specific subpopulations are underrepresented, such as very young, female, and non-white patients. ${ }^{3}$ Second, most RCTs comparing PCI and CABG have limited follow-up, usually reporting outcomes up to 5 years only. ${ }^{7}$ Lastly, the funding of RCTs comparing PCI and CABG has often come from industry. RCTs supported by industry are more likely to be positive than studies funded through other means, which suggest that biases

\footnotetext{
From the ${ }^{\mathrm{a}}$ Division of Cardiac Surgery, Department of Surgery, Schulich Heart Centre, Sunnybrook Health Sciences Centre; and ${ }^{b}$ Institute of Health Policy, Management and Evaluation, University of Toronto, Toronto, Ontario, Canada.

Disclosures: Dr Tam is supported by a CIHR Fellowship (Canada). Dr Fremes is supported by the Bernard S. Goldman Chair in Cardiovascular Surgery (Toronto, Ontario). All other authors reported no conflicts of interest.

The Journal policy requires editors and reviewers to disclose conflicts of interest and to decline handling or reviewing manuscripts for which they may have a conflict of interest. The editors and reviewers of this article have no conflicts of interest.

Received for publication April 11, 2020; revisions received April 11, 2020; accepted for publication April 13, 2020; available ahead of print May 6, 2020.

Address for reprints: Stephen E. Fremes, MD, MSc, Schulich Heart Centre, Sunnybrook Health Sciences Centre, 2075 Bayview Ave, Room H4 05, Toronto,

Ontario, M4N 3M5, Canada (E-mail: stephen.fremes@sunnybrook.ca).

J Thorac Cardiovasc Surg 2022;163:657-8

$0022-5223 / \$ 36.00$

Copyright (c) 2020 by The American Association for Thoracic Surgery

https://doi.org/10.1016/j.jtcvs.2020.04.108
}

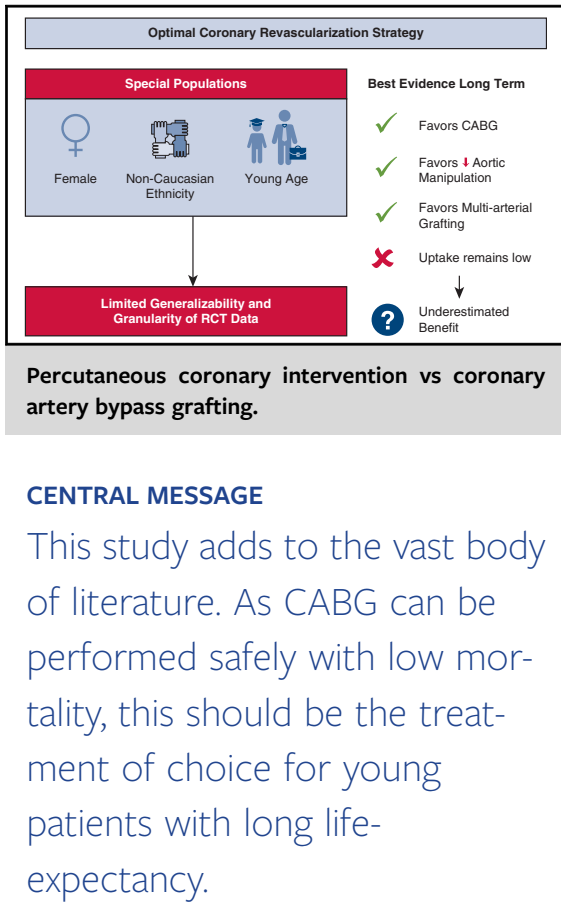

may exist in the design or implementation phases. Also, there is a strong advantage for industry to have an early study answer, whereas the relative benefit from CABG may come later. ${ }^{8-10}$

Robich and colleagues ${ }^{11}$ compare the early and late outcomes of CABG versus PCI in patients younger than 60 years from the registries of the Northern New England Cardiovascular Disease Study Group (NNECDSG), with up to 10 -years of follow-up. ${ }^{11}$ The investigators must be congratulated for their effort to evaluate this question, which address the main RCT's limitations, mentioned previously. Despite the shortcomings of a retrospective analysis using non-mandatory databases, we wish to highlight multiple interesting points in this study.

The study's patient population of complex multivessel coronary artery disease (2-vessel disease with left anterior descending [LAD] artery involvement and 3-vessel disease) comprised 4883 cases. Exclusions included left main $\geq 50 \%$, ST-elevation myocardial infarction, cardiogenic shock, emergency status, younger than 25 years of age, previous PCI or previous cardiac surgery, and patients who had an additional procedure along with the $\mathrm{CABG}$, ie, conditions in which there may be a strong preference for one form of revascularization. From this group, 2938 of 4883 $(60.2 \%)$ underwent PCI. Before adjustment, patients were younger, and there was a greater prevalence of female patients in the PCI group. Young patients might prefer PCI 
over CABG, since they can resume work and physical activity earlier, which might have influenced the choice of treatment strategy in this study. Nonetheless, we were still surprised by the high proportion of patients undergoing PCI, as the 2011 and 2012 American College of Cardiology Foundation/American Heart Association guidelines recommend CABG as a Class I indication for patients with 3-vessel disease and 2-vessel disease with proximal LAD, and Class IIa for 2-vessel without proximal LAD cases in patients with stable ischemic heart disease. Although PCI is often appropriate in patients presenting with acute coronary syndromes, PCI is recommended only as Class IIb (uncertain benefit) for the entire study patient population. ${ }^{12}$

One of the main CABG disadvantages is the upfront greater risk compared with PCI. Robich and colleagues describe excellent 30-day results, with no differences in early mortality. Perhaps the expected greater early mortality with CABG compared with PCI in an unselected population is not actually observed in younger patients. Nonetheless, even after risk-adjustment, stroke remained greater in the CABG group $(1.2$ vs $0.05 \%, P<.001)$ in this young cohort. The authors did not provide surgical details such as aortic manipulation (on pump, off-pump, use of side-biding clamp), although we do know that bilateral internal mammary usage was low, a strategy that is usually associated with less aortic manipulation. ${ }^{13}$ An important message from the analysis of Robich and colleagues is that surgeons should always strive to employ techniques to minimize the risk of perioperative stroke, even in a young population (which would have theoretically low risk of this adverse event).

CABG was associated with better 10-year results. In the current study, the proportional hazards assumption was violated, as it typically occurs when comparing CABG versus PCI (greater early hazards with CABG following greater late hazards with PCI). Hence, the analysis was dichotomized into the first 6 months, with no difference in the outcomes, and after 6 months, which showed an association of CABG with better outcomes. Given the advantage of completeness of revascularization and protection against non-flow-limiting lesions, CABG is usually associated with improved long-term results compared with PCI. ${ }^{14}$

The low use of multiarterial grafting in this young population with an anticipated long life-expectancy is disappointing. Although the advantages of multiarterial grafting remain uncertain in older patients, the patient cohort included in this analysis would almost certainly be candidates for a multiarterial strategy. ${ }^{15}$ The observed results may have even more favorable in the CABG population with a multiarterial grafting strategy, as suggested by most observational studies. ${ }^{16,17}$ In the PCI group, we have no data regarding the use of drug-eluting stents. These stents have been associated with improved results compared with bare-metal stents, and it's uncertain whether in the early era of this study (2005-2010), drug-eluting stents were routinely used to treat the PCI group. ${ }^{18}$

In the continuing debate of which is the best revascularization strategy for complex coronary disease, the study of Robich and colleagues adds to the vast body of literature. As CABG can be performed relatively safely with low mortality, this should be the treatment of choice for young patients with long life expectancy.

\section{References}

1. Favaloro RG. Saphenous vein autograft replacement of severe segmental coronary artery occlusion: operative technique. Ann Thorac Surg. 1968;5:334-9.

2. Gruntzig A. Transluminal dilatation of coronary-artery stenosis. Lancet. 1978;1: 263.

3. Serruys PW, Morice MC, Kappetein AP, Colombo A, Holmes DR, Mack MJ, et al. Percutaneous coronary intervention versus coronary-artery bypass grafting for severe coronary artery disease. N Engl J Med. 2009;360:961-72.

4. Fischman DL, Leon MB, Baim DS, Schatz RA, Savage MP, Penn I, et al. A randomized comparison of coronary-stent placement and balloon angioplasty in the treatment of coronary artery disease. Stent restenosis study investigators. $N$ Engl J Med. 1994;331:496-501.

5. Farkouh ME, Domanski M, Sleeper LA, Siami FS, Dangas G, Mack M, et al. Strategies for multivessel revascularization in patients with diabetes. $N$ Engl J Med. 2012;367:2375-84.

6. Mohr FW, Morice MC, Kappetein AP, Feldman TE, Stahle E, Colombo A, et al. Coronary artery bypass graft surgery versus percutaneous coronary intervention in patients with three-vessel disease and left main coronary disease: 5-year follow-up of the randomised, clinical SYNTAX trial. Lancet. 2013;381:629-38.

7. Stone GW, Kappetein AP, Sabik JF, Pocock SJ, Morice MC, Puskas J, et al. Fiveyear outcomes after PCI or CABG for left main coronary disease. $N$ Engl J Med. 2019;381:1820-30.

8. Ahn R, Woodbridge A, Abraham A, Saba S, Korenstein D, Madden E, et al. Financial ties of principal investigators and randomized controlled trial outcomes: cross sectional study. BMJ. 2017;356:i6770.

9. Ridker PM, Torres J. Reported outcomes in major cardiovascular clinical trials funded by for-profit and not-for-profit organizations: 2000-2005. JAMA. 2006; 295:2270-4.

10. Lundh A, Lexchin J, Mintzes B, Schroll JB, Bero L. Industry sponsorship and research outcome. Cochrane Database Syst Rev. 2017;2:MR000033.

11. Robich MP, Leavitt BJ, Ryan TJ Jr, Westbrook BM, Malenka DJ, Gelb DJ, et al. Comparative effectiveness of revascularization strategies for early coronary artery disease: a multi-center analysis. J Thorac Cardiovasc Surg. 2022;163: 645-56.e2.

12. Kolh P, Kurlansky P, Cremer J, Lawton J, Siepe M, Fremes S. Transatlantic editorial: a comparison between European and North American guidelines on myocardial revascularization. J Thorac Cardiovasc Surg. 2016;152:304-16.

13. Zhao DF, Edelman JJ, Seco M, Bannon PG, Wilson MK, Byrom MJ, et al. Coronary artery bypass grafting with and without manipulation of the ascending aorta: a network meta-analysis. J Am Coll Cardiol. 2017;69:924-36.

14. Doenst T, Haverich A, Serruys P, Bonow RO, Kappetein P, Falk V, et al. PCI and $\mathrm{CABG}$ for treating stable coronary artery disease: JACC review topic of the week. J Am Coll Cardiol. 2019;73:964-76.

15. Aldea GS, Bakaeen FG, Pal J, Fremes S, Head SJ, Sabik J, et al. The Society of Thoracic Surgeons clinical practice guidelines on arterial conduits for coronary artery bypass grafting. Ann Thorac Surg. 2016;101:801-9.

16. Rocha RV, Tam DY, Karkhanis R, Nedadur R, Fang J, Tu JV, et al. Multiple arterial grafting is associated with better outcomes for coronary artery bypass grafting patients. Circulation. 2018;138:2081-90.

17. Yi G, Shine B, Rehman SM, Altman DG, Taggart DP. Effect of bilateral internal mammary artery grafts on long-term survival: a meta-analysis approach. Circulation. 2014;130:539-45.

18. Sarno G, Lagerqvist B, Frobert O, Nilsson J, Olivecrona G, Omerovic E, et al. Lower risk of stent thrombosis and restenosis with unrestricted use of 'new-generation' drug-eluting stents: a report from the nationwide Swedish coronary angiography and angioplasty registry (SCAAR). Eur Heart J. 2012; 33:606-13. 